TRÊS FORMAS DE AMAR: A CONSTRUÇÃO DA IMAGEM DE NEYMAR JR NO MERCADO BRASILEIRO DE REVISTAS

Luís Henrique Mendonça Ferraz

José Carlos Marques

\title{
TRÊS FORMAS DE AMAR: A CONSTRUÇÃO DA IMAGEM DE NEY- MAR JR NO MERCADO BRASILEIRO DE REVISTAS
}

\section{THREE WAYS TO LOVE: THE NEYMAR JR IMAGE'S CONSTRUCTU- ION IN THE BRAZILIAN MAGAZINE MARKET}

\author{
Luís Henrique Mendonça Ferraz ${ }^{1}$ \\ José Carlos Marques ${ }^{2}$
}

\begin{abstract}
RESUMO: Este artigo tem como finalidade analisar a construção discursiva realizada pela imprensa brasileira a respeito de Neymar Jr., futebolista que iniciou sua carreira no Santos FC e que atualmente defende o Paris Saint-Germain e a Seleção Brasileira. Nosso objetivo é abordar, por meio da Análise do Discurso de linha francesa, como o mercado brasileiro de revistas construiu a imagem do atleta nas publicações de 2010 a 2012, período de consolidação da carreira como craque bem-sucedido no Brasil. Nestes anos, Neymar Jr. esteve presente em pelo menos 22 capas de revistas brasileiras, de diferentes gêneros e temáticas, a partir de uma construção discursiva sistêmica, eufórica e convergente. Com sua ida para o exterior em 2013, o processo de exposição nas capas de revistas brasileiras reduziu-se, ao mesmo tempo em que o atleta ganhou nova dimensão no mercado global futebolístico.
\end{abstract}

Palavras-chave: Neymar Jr. jornalismo de revista. idolatria.

ABSTRACT: This article aims to address the discursive construction carried out by the Brazilian press about Neymar Jr., a footballer who started his career at Santos FC and currently defends Paris Saint-Germain and the Brazilian National Team. Our objective is to approach, through the French Speech Discourse Analysis, how the Brazilian market of magazines con-

\footnotetext{
1 Mestre em Comunicação pela Universidade Estadual Paulista Júlio de Mesquita Filho (FAACUnesp/Bauru). E-mail: luishferraz@yahoo.com.br

2 Doutor em Ciências da Comunicação pela Escola de Comunicações e Artes da Universidade de São Paulo. É Docente do Programa de Pós-graduação em Comunicação e do Departamento de Ciências Humanas da Faculdade de Arquitetura, Artes e Comunicação da Universidade Estadual Paulista (Unesp/Bauru). E-mail: zeca.marques@faac.unesp.br
} 


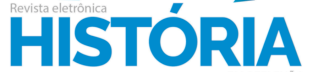

TRÊS FORMAS DE AMAR: A CONSTRUÇÃO DA IMAGEM DE NEYMAR JR NO MERCADO BRASILEIRO DE REVISTAS

Luís Henrique Mendonça Ferraz

José Carlos Marques

structed the image of the athlete in covers of different publications of the country from 2010 to 2012 , during which time the player initiated a process of sedimentation of the career as a successful player in Brazil. In these years, Neymar Jr. was present in at least 22 covers of Brazilian magazines, of different genres and themes, from a systemic discursive construction, euphoric and convergent. With his move abroad in 2013, the process of exposure on Brazilian magazine covers was reduced, while the athlete gained a new dimension in the global football market.

Key-words: Neymar Jr. magazine journalism. idolatry. Introdução

Este artigo tem como finalidade analisar a construção discursiva realizada pela imprensa brasileira a respeito de Neymar Jr., futebolista que iniciou sua carreira no Santos FC e que atualmente defende o Paris Saint-Germain e a Seleção Brasileira. Nosso objetivo é abordar, por meio da Análise do Discurso de linha francesa, como o mercado brasileiro de revistas construiu a imagem do atleta em capas de diferentes publicações do país de 2010 a 2012, período em que o jogador iniciou um processo de sedimentação da carreira como craque bem-sucedido no Brasil, antes de se transferir para o futebol europeu.

O corpus de análise refere-se ao tirênio 2010, 2011 e 2012, período que remonta à ascensão do jogador antes de transferir-se para o Bacelona. Nestes anos, Neymar Jr. esteve presente em pelo menos 23 capas de revistas brasileiras, de cinco gêneros jornalísticos diferentes, a saber: o segmento esportivo, o segmento masculino, o segmento feminino, o segmento feminino adolescente e o segmento de variedades. Em quase todos os casos, temos uma construção discursiva sistêmica, eufórica e convergente da imagem do jogador.

A análise do mercado de revistas brasileiro concede uma oportunidade ímpar de interpretação por sua especificidade como meio de comunicação - que opta habitualmente por veicular em suas "primeiras páginas" a vida de grandes personagens do cotidiano que são elevados ao status de celebridade. Geralmente, ao escolherem determinados ícones do entretenimento, as publicações utilizam da confiabilidade que possuem com seu público - já que estamos falando de um veículo de comuni- 


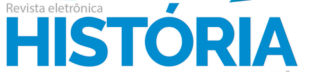

TRÊS FORMAS DE AMAR: A CONSTRUÇÃO DA IMAGEM DE NEYMAR JR NO MERCADO BRASILEIRO DE REVISTAS

Luís Henrique Mendonça Ferraz

José Carlos Marques

cação que se dirige para conjuntos de pessoas mais exclusivos, por assim dizer para demonstrar, por meio dos personagens previamente "escolhidos", os novos padrões de comportamento, moda e estilo de vida.

Com o auxílio da Análise do Discurso de linha francesa, explicaremos detaIhadamente como as formações discursivas (verbais e não verbais) produzidas pelo mercado de revistas nacional foram decisivas para a promoção do jogador Neymar Jr. à condição de celebridade. Com enorme frequência, o segmento impresso do país personificou o seu "eleito" por meio de algumas reiterações/repetições discursivas e imagéticas, tais quais: do famoso, do rico, do belo, do astro bem-sucedido ou do gênio da bola. Por consequência, temos na estruturação midiática de Neymar Jr. um personagem que se tornou referência para os adolescentes, o objeto de desejo para as mulheres e a personificação do sucesso profissional para os adultos. E, seguindo na progressão das análises das revistas brasileiras, temos a perpetuação de uma personalidade - representação midiática - que foi materializada como ídolo esportivo, como sex symbol e como homem de sucesso, compondo-se o que chamamos de "três formas de amar" a celebridade.

Neymar da Silva Souza Júnior, mais conhecido como Neymar ou Neymar Júnior, é um jogador de futebol brasileiro nascido em 5 de fevereiro de 1992 e que, atualmente, defende o Paris Saint-Germain FC. Seu desenvolvimento como atleta esteve intimamente ligado ao Santos FC, agremiação em que atuou desde as categorias de base como atacante e que promoveu a estreia do jogador como profissional aos 17 anos, em jogo válido pelo Campeonato Paulista de 2009. No clube, entre os anos de 2009 e 2013, Neymar Jr. foi tricampeão Paulista (2010/2011/2012), campeão da Copa do Brasil de 2010 e, ainda, venceu a Copa Libertadores da América de 2011, título mais cobiçado pelos clubes da América do Sul (este último feito esportivo não era obtido pelo Santos FC desde a época de Pelé, considerado o maior jogador da história do Santos e da Seleção Brasileira de Futebol).

No segundo ano como futebolista profissional, em 2010, Neymar Jr. foi con- 


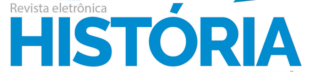

TRÊS FORMAS DE AMAR: A CONSTRUÇÃO DA IMAGEM DE NEYMAR JR NO MERCADO BRASILEIRO DE REVISTAS

Luís Henrique Mendonça Ferraz

José Carlos Marques

vocado para a seleção brasileira e, assim, foi apenas uma questão de tempo para que o jogador fosse "eleito" - em especial, pelos jornalistas e cronistas esportivas como atleta fora de série, o protótipo do craque brasileiro. Além das conquistas e títulos coletivos nos anos em que vestiu a camisa da equipe santista, o jogador também foi premiado por seu desempenho individual, sendo artilheiro da Copa do Brasil 2010, do Campeonato Paulista de 2012 e da Copa Libertadores da América de 2012, conquistando, ainda, o prêmio FIFA Ferenc Puskás ${ }^{3}$ de 2012.

O fenômeno midiático Neymar Jr., intitulado pelos veículos de comunicação brasileiros como "Neymarmania", revela em essência, a veneração de um personagem - inicialmente - pertencente apenas à esfera futebolística. Logo, a euforia em torno do jogador Neymar Jr., certamente, não é inaugural dentro do cenário futebolístico e midiático brasileiro. Assim sendo, a narrativa Neymar Jr. pode ser considerada a atualização do craque à brasileira; uma aproximação histórica entre passado e o presente, entre os antigos e os novos ídolos do esporte no país. Em comum, os "craques" brasileiros como Pelé, Zico, Romário, Ronaldo e, agora, Neymar Jr., partiIham de uma trajetória de vida semelhante: no caso, a origem pobre, a infância simples e o talento de jogar bola. Tais características potencializam a identificação entre o público/espectador e os craques, são "povo para o povo", como já salientou o antropólogo Simoni Lahud Guedes (1995), no artigo O Salvador da pátria: considerações em torno da imagem do jogador Romário na Copa do Mundo de 1994.

Podemos elencar ainda algumas características que aproximam Neymar Jr. de outras estrelas futebolísticas e midiáticas, como: Zico, Romário e Ronaldo. Em A construção de narrativas de idolatria do futebol brasileiro, Ronaldo Helal (2003) aborda a possibilidade de idolatria alcançada tanto pelo trabalho, determinação e esforço, de Zico, quanto da genialidade, irreverência e malandragem, de Romário.

\footnotetext{
${ }^{3}$ Premiação concedida pela Federação Internacional de Futebol (FIFA) ao autor do gol mais bonito do mundo no ano. O troféu leva o nome do lendário jogador húngaro Ferenc Purczeld Biró, mais conhecido como Puskás, considerado um dos melhores jogadores do mundo nas décadas de 1950 e 1960.
} 


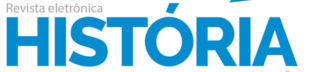

TRÊS FORMAS DE AMAR: A CONSTRUÇÃO DA IMAGEM DE NEYMAR JR NO MERCADO BRASILEIRO DE REVISTAS

Luís Henrique Mendonça Ferraz

José Carlos Marques

No caso Neymar Jr., temos um jovem que desde os 14 anos de idade foi preparado e moldado para ser um jogador reconhecido mundialmente - a lembrar, teve suporte educacional e psicológico, aulas de idiomas e preparação física diferenciada dos demais atletas brasileiros de sua geração -, assim como Zico, Neymar também pode ser considerado "craque de laboratório". Igualmente, vemos em Neymar Jr. a "genialidade e irreverência" de Romário - de uma transgressão positiva tão aceita, valorizada e identificada com o futebol brasileiro.

De Ronaldo "Fenômeno", Neymar Jr. "herda" o entendimento do futebol como negócio. Sobre o jogador Ronaldo Nazário, Marques (2005) já salientava um projeto midiático e de marketing para que o craque fosse reconhecido nas mais longínquas localidades no planeta. De maneira similar, Neymar Jr, tem sua imagem protegida a todo custo pelos meios de comunicação brasileiros, em especial, por ser garotopropaganda de multinacionais. É reconhecido como uma estrela mundial e possui milhões de seguidores no Instagram - é um influenciador digital.

Neymar Jr. carrega a genética do "craque" brasileiro. Como consequência do sucesso nos gramados e dos interesses econômicos dos meios de comunicação, Neymar Jr. foi "transformado" em celebridade por outros tantos e múltiplos conteúdos e programas da mídia brasileira. Dentre os vários elementos que possibilitam sua projeção midiática, um detalhe nos chama a atenção: a instantaneidade e a intensidade com que o jogador/celebridade foi projetado pela mídia - dada a crescente reverberação do protagonista nos meios de comunicações brasileiros.

A consolidação midiática de Neymar Jr. tem como mote a criação de uma estrela/celebridade, de uma figura central para o esporte e o entretenimento nacional. No entanto, deve-se ter em mente que o espetáculo midiático não se caracteriza pela imposição efusiva na gestão do fazer diário dos consumidores, mas pela possibilidade de influenciar através dos conteúdos midiáticos elaborados minuciosamente que, por meio de textos, imagens e sons, negociam novos modos de pertencimento na contemporaneidade. Amiúde, a "construção" dos personagens midiáticos atende 
HISTÓRIA

TRÊS FORMAS DE AMAR: A CONSTRUÇÃO DA IMAGEM DE NEYMAR JR NO MERCADO BRASILEIRO DE REVISTAS

Luís Henrique Mendonça Ferraz

José Carlos Marques

indiscutivelmente uma demanda/tendência prévia, programada e específica dos veículos de comunicação. Nesse contexto, a concepção de Neymar Jr. como ícone nacional surge do ensejo da mídia brasileira por um grande representante que estabeleça vínculo mercadológico e de verossimilhança com público. Portanto, a mídia dá ênfase a determinadas particularidades da personalidade de Neymar Jr., abordando apenas as facetas que julgue proveitosas para a "elaboração" de um protagonista/produto atraente.

O apelo midiático adquirido pelo atleta concebe, de forma poucas vezes vistas, um estrelato meteórico. Em pouco mais de três anos, a exacerbada exposição midiática de um jovem e promissor jogador de futebol brasileiro consegue fazer com que ele seja reverenciado como um potente ícone e celebridade nacional. Trata-se de um protagonista que transcende públicos, gêneros jornalísticos, faixas-etárias e classes sociais, em outras palavras, da construção de uma narrativa sistêmica dentro dos meios de comunicação, de um ícone preparado e concebido para coabitar mentes e corações do maior número possível de pessoas da plateia brasileira.

O que conhecemos do personagem Neymar Jr. é resultado de uma elaborada estratégia midiática convergente que existe entre os vários meios de comunicação nacionais; lembrando que o personagem em questão conquista "noticiabilidade" em quase todos os conteúdos jornalísticos e de entretenimento existentes na mídia brasileira. Soma-se ainda o fato de que o portento midiático do jogador/celebridade se distingue pela capacidade de novelização - história longa e aventuresca -, de uma figura constantemente julgada e absolvida nos conteúdos orquestrados pelos meios de comunicação. Outra menção importante é proposição da jornada midiática de Neymar Jr. não como um produto inacabado, mas, sim, como uma narrativa traçada diariamente - levando em consideração as conquistas do personagem tanto no âmbito esportivo, quanto na vida particular, que repercutam dentro do espetáculo midiático.

O protagonismo do jogador/celebridade é facilmente observável por toda a 


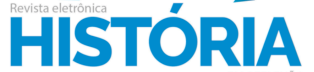

TRÊS FORMAS DE AMAR: A CONSTRUÇÃO DA IMAGEM DE NEYMAR JR NO MERCADO BRASILEIRO DE REVISTAS

Luís Henrique Mendonça Ferraz

José Carlos Marques

grade de programação da televisão, pelo mercado brasileiro de revistas e pela internet, além do interesse tanto dos anunciantes locais, quanto globais. Logo, a curta trajetória como jogador profissional e o progressivo interesse midiático envolto à figura do jogador/celebridade - sobretudo pela segmentação noticiosa/informacional conferida ao personagem -, transpõem a imagem de Neymar Jr. de um segmento inicialmente restrito ao jornalismo esportivo (profissional de futebol) para outros programas/conteúdos do entretenimento nacional (celebridade). Vislumbramos ainda que o ponto chave do estrelato do personagem é a multiplicidade de produtos midiáticos que estão vinculados à personalidade da "estrela" - da encenação e representação midiática que compõem o protagonismo do jogador/celebridade. No livro $A$ Cultura da Mídia, Douglas Kellner (2004) enfatiza que a "construção" das celebridades é prontamente abalizada e mediada pela mídia. $\mathrm{O}$ autor revela que toda personalidade da midiática deve ser confirmada pela sua representatividade e/ou valor na esfera cotidiana, ou seja, que o rito de passagem ao "mundo estelar" é confirmado por aqueles que possuem destaque em determinado cargo, função e/ou profissão. Para Kellner [...]

A celebridade também é produzida e manipulada pelo mundo do espetáculo [...] Para alguém se tornar uma celebridade é preciso ser reconhecida como uma estrela no campo do espetáculo, seja no esporte, no entretenimento, ou na política. As celebridades têm seus assessores e articuladores para assegurar que suas imagens continuem a ser vistas de forma positiva pelo público (KELLNER, 2004, p.06).

A representação midiática de Neymar Jr. imbui-se de programar uma nova "estrela do espetáculo", tanto para o tempo presente quanto para o futuro, dada à baixa idade e as características biográficas do jogador/celebridade. Outra particularidade constatada são os programas/produtos corporificados pelo personagem, desde o protagonismo exercido em capítulos pontuais nas minisséries/novelas voltadas para os públicos adulto e adolescente, até a presença do personagem em progra- 
HISTÓRIA

TRÊS FORMAS DE AMAR: A CONSTRUÇÃO DA IMAGEM DE NEYMAR JR NO MERCADO BRASILEIRO DE REVISTAS

Luís Henrique Mendonça Ferraz

José Carlos Marques

mas de auditório e nos talk shows de enorme audiência, de diferentes gêneros/temáticas de informação e constantes no entretenimento nacional.

Considerando ainda o desempenho midiático de Neymar Jr. na grade de programação da TV brasileira, a imagem do ícone, de maneira perceptível, está associada aos anunciantes nacionais e mundiais - marcas que financiam toda a produção da mídia nacional. Ao menos onze empresas associaram sua imagem coorporativa à do jogador entre os anos de 2010 e 2012. Dentre elas, temos produtos de vestimenta e artigos esportivos, do mercado de tecnologia/telefonia, da indústria automotiva, de bebidas, de bancos, de comida, de higiene e de limpeza. Trata-se da participação ativa do jogador/celebridade como validador/propulsor de marcas mundialmente conhecidas em território nacional. Outro dado relevante que deve ser ressaltado é a comercialização de um produto midiático, de um Neymar Jr. "negociado/vendido" dos pés a cabeça, do protagonismo como garoto-propaganda das cadeias e bens de consumo que possuem notoriedade como líderes de mercado, condição e autoridade semelhantes à do personagem no período. Tal condição não é novidade no mundo do espetáculo midiático contemporâneo e já foi tema dos estudos de Edgar Morin, mais precisamente na obra As estrelas: mito e sedução no cinema. Para Morin $[\ldots]$

\footnotetext{
Não há um centímetro de seu corpo, uma fibra de sua alma ou uma recordação de sua vida que não possa ser lançada no mercado [...] $\mathrm{A}$ estrela tem todas as virtudes dos produtos fabricados em série e adotados no mercado mundial, como o chiclete, a geladeira, o detergente, o barbeador, etc. A difusão maciça é assegurada pelos maiores disseminadores do mundo moderno, a imprensa, o rádio e, evidentemente, o filme (MORIN, 1989, p. 76).
}

Vemos aqui como Neymar Jr. enquadra-se neste paradigma de corpo mercantilizado: suas roupas, bonés, óculos e calçados são pensados de forma a manter a exposição das marcas ou do estilo de vida de seus anunciantes. De maneira concomitante, ora promoveu/promove seus patrocinadores; ora foi/é promovido por eles. 


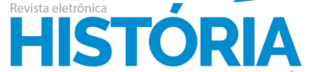

TRÊS FORMAS DE AMAR: A CONSTRUÇÃO DA IMAGEM DE NEYMAR JR NO MERCADO BRASILEIRO DE REVISTAS

Luís Henrique Mendonça Ferraz

José Carlos Marques

Decisivamente, a onipresença de Neymar Jr. na mídia brasileira não foi mero acidente; foi uma programação muito bem pensada e articulada. De 2010 a 2012, Neymar Jr. esteve em nossos lares; esteve em nossas vidas. E quando nos demos conta, já conhecíamos toda a trajetória de vida da nova celebridade brasileira. Afinal de contas, quem não conhece o Neymar Jr. no Brasil?

\section{A trajetória de neymar jr. No mercado brasileiro de revistas}

Os feitos célebres e heroicos das personalidades - da pré-comunicação à comunicação midiática - possuem uma particularidade: o discurso. Toda história contada precisa de uma legitimação por meio da palavra, precisa de alguém que dê validade ao discurso. Nota-se nas construções discursivas relacionadas às figuras públicas a importância da mediação, ou seja, da relação de confiabilidade estabelecida entre os interlocutores do discurso.

Atualmente, a ascensão e a queda das celebridades passam inevitavelmente pela produção midiática. Desse modo, as celebridades são produzidas e validadas de acordo com os interesses institucionais dos principais conglomerados de comunicação nacionais e internacionais. De certa forma, a indústria do entretenimento é uma via de mão dupla: tanto pode conceder vida longa à celebridade quanto pode devolve-la anonimato.

Entre os anos de 2010 e 2012 Neymar Jr. foi capa de, pelo menos, 22 revistas nacionais comerciais (excluímos, assim, as publicações empresariais que são distribuídas quase que invariavelmente de forma gratuita, como é o caso de revistas de bordo de companhias de aviação, por exemplo). Temos aqui um número surpreendente, levando-se em consideração os gêneros jornalísticos distintos ${ }^{4}$ que veicula-

\footnotetext{
4 Definimos o segmento das revistas e, consequentemente, o público-alvo, como: a) Revistas esportivas - Placar e ESPN; b) Revista Semanal (Variedades) - Veja, Época, IstoÉ e Brasileiros; c)
} 


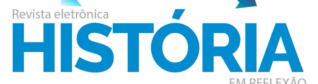

TRÊS FORMAS DE AMAR: A CONSTRUÇÃO DA IMAGEM DE NEYMAR JR NO MERCADO BRASILEIRO DE REVISTAS

Luís Henrique Mendonça Ferraz

José Carlos Marques

ram a ascensão e a celebração do jogador em território nacional.

Em 2010, as publicações nacionais destacavam a carreira de jogador de futebol em ascensão, ou seja, levava-se em consideração o ato inaugural, o surgimento de uma nova promessa para o futebol brasileiro. Em seu primeiro ano como profissional, o jogador de futebol estampou um total de cinco capas, sendo três publicações do segmento esportivo - no caso, as edições da revista Placar n 1341 e n 1349, e a edição da revista $E S P N n^{0} 12$. Os outros exemplares do ano de 2010 , são: a revista $T R I P$, edição $n^{\circ} 189$ e a revista de variedades Época, edição $n^{\circ} 656$. A capa da revista Época foi primeira a eleger Neymar Jr. como "vitorioso", relacionando o jogador a outros três personagens extremamente midiáticos e também "eleitos" como os "brasileiros mais influentes" do ano pela publicação (a saber, a presidente Dilma Roussef, o cineasta José Padilha e o empresário Eike Batista).

No ano de 2011, a veiculação da imagem do jogador esteve presente em nove capas de revistas. A grande particularidade apresentada pelas publicações do ano é a transcendência da figura de Neymar Jr., inicialmente relacionada aos feitos esportivos e que, no período, ganha novas temáticas, estrelando edições cada vez mais plurais, de segmentos e públicos-alvo diversos. Das nove revistas brasileiras publicadas em 2011 apenas duas são esportivas. As demais edições são: Alfa, edição $n^{\circ} 09$, Capricho, edição $n^{\circ} 1125$, Istoé, edição $n^{\circ} 2172$, Veja, edição $n^{\circ} 2223$, Atrevida, edição $n^{\circ}$ 203, AtrevidaGO, edição n²08, e TPM, edição $n^{\circ} 116$.

Em 2012, ano de disputa dos Jogos Olímpicos de Londres, a figura de Neymar Jr. foi compartilhada por oito capas de revistas, das quais metade pertenciam ao segmento esportivo - a saber, ESPN, edição $n^{\circ} 30, E S P N$, edição $n^{\circ} 33$, Placar, edição $n^{\circ} 1368$, Placar, $n^{\circ}$ 1371. As outras quatro publicações, são: Charme, edição $n^{\circ}$ 16, Loveteen, edição $n^{a} 74$, Veja, edição especial $n^{\circ} 2278$ e Brasileiros, edição $n^{\circ} 59$.

O quadro a seguir lista as revistas em que Neymar foi capa no Brasil de 2010

Revistas masculinas - Trip e Alfa; d) Revistas femininas - TPM e Contigo!; Revistas feminina adolescente (público teen) - Capricho, Atrevida, AtrevidaGO, Charme e Loveteen. 


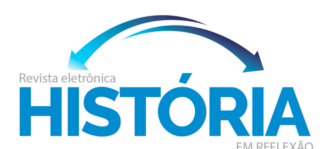

TRÊS FORMAS DE AMAR: A CONSTRUÇÃO DA IMAGEM DE NEYMAR JR NO MERCADO BRASILEIRO DE REVISTAS

Luís Henrique Mendonça Ferraz

José Carlos Marques

a 2012, antes de transferir-se para o Barcelona.

Quadro 1: Relação de revistas brasileiras com Neymar na capa

\begin{tabular}{|c|c|c|c|}
\hline REVISTAS & MÊSIANO & SEGMENTO & TíTULO \\
\hline Placar Edição Especial & abril/2010 & Esportivo & Especial 40 anos Santos FC \\
\hline Trip & junho/2010 & Masculino & Porra, Dunga! \\
\hline ESPN & outubro/2010 & Esportivo & Neymar: Gênio ou monstro? \\
\hline Placar & dezembro/2010 & Esportivo & Brasil Olímpico \\
\hline Época Ed. Especial & dezembro/2010 & Variedades & 100 \\
\hline Alfa & maio/2011 & Masculino & O Complexo de Neymar \\
\hline Capricho & junho/2011 & $\begin{array}{c}\text { Feminino (público } \\
\text { teen) }\end{array}$ & Neymar \\
\hline Placar & junho/2011 & Esportivo & Rei? \\
\hline Istoé & junho/2011 & Variedades & $\begin{array}{l}\text { O mundo particular de Ney- } \\
\text { mar }\end{array}$ \\
\hline Veja & junho/2011 & Variedades & “REYMAR” \\
\hline Atrevida & julho/2011 & $\begin{array}{l}\text { Feminino (público } \\
\text { teen) }\end{array}$ & Neymar de atitude \\
\hline Atrevida GO & dezembro/2011 & $\begin{array}{l}\text { Feminino (público } \\
\text { teen) }\end{array}$ & Neymar \#euquero \\
\hline TPM & dezembro/2011 & Feminino & Neymar é nosso \\
\hline Placar & dezembro/2011 & esportiva & Te cuida, Messi! \\
\hline Charme & janeiro/2012 & $\begin{array}{l}\text { Feminino (público } \\
\text { teen) }\end{array}$ & Ele é craque! Neymar \\
\hline Loveteen & fevereiro/2012 & $\begin{array}{c}\text { Feminino (público } \\
\text { teen) }\end{array}$ & Neymar \\
\hline ESPN & abril/2012 & Esportivo & $\begin{array}{l}\text { Todos querem a camisa de } \\
\text { Neymar }\end{array}$ \\
\hline Brasileiros & junho/2012 & Variedades & Alegria e arte no futebol \\
\hline
\end{tabular}


HISTÓRIA

TRÊS FORMAS DE AMAR: A CONSTRUÇÃO DA IMAGEM DE NEYMAR JR NO MERCADO BRASILEIRO DE REVISTAS

Luís Henrique Mendonça Ferraz

José Carlos Marques

\begin{tabular}{|c|c|c|c|}
\hline ESPN & julho/2012 & Esportivo & Apostas de ouro \\
\hline Placar & julho/2012 & Esportivo & Na pressão \\
\hline $\begin{array}{c}\text { Veja Edição Especial Jo- } \\
\text { gos Olímpicos }\end{array}$ & julho/2012 & Variedades & Londres \\
\hline Placar & outubro/2012 & Esportivo & A crucificação de Neymar \\
\hline
\end{tabular}

Fonte: Tabela elaborada pelos autores.

Nota-se, na apreciação do material coletado, a ampliação do número de publicações quando comparadas ao ano de projeção da carreira de Neymar Jr. É preciso destacar que, em 2009, Neymar Jr. estreia com a camisa do Santos FC, porém ainda como jogador reserva do time. São as posteriores conquistas esportivas, em 2010, que impulsionam a disseminação de produtos e programas presentes nos meios de comunicação de massa. Com o estrelato na esfera esportiva, os conteúdos que envolvem a participação de Neymar Jr. crescem exponencialmente - fato que culmina no protagonismo do jogador nas capas de revistas do mesmo ano, o primeiro do recorte da pesquisa. Se comparados ao ano de 2010 , é notável o aumento em números das publicações dos anos seguintes, 2011 e 2012.

Podemos afirmar também que o número de capas de revistas voltadas ao universo esportivo é superado pela soma dos demais segmentos jornalísticos encontrados na pesquisa (no caso, as revistas masculinas, as revistas femininas, as revistas adolescentes femininas e de variedades). É interessante notarmos que a imagem de Neymar Jr. transita de forma pendular entre os segmentos jornalísticos.

Acreditamos que os segmentos e temáticas das revistas em questão reproduzam o personagem Neymar Jr. em frentes diversas. Assim sendo, temos diferentes discursos, diferentes segmentos jornalísticos e públicos que dialogam com o personagem, de modo que os sentidos e a incorporação do protagonista ganham corpo (tomam forma) no processo que resulta de interação entre os produtores do texto e os leitores.

Igualmente, temos na "construção" do protagonismo de Neymar Jr., nas revis- 


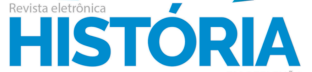

TRÊS FORMAS DE AMAR: A CONSTRUÇÃO DA IMAGEM DE NEYMAR JR NO MERCADO BRASILEIRO DE REVISTAS

Luís Henrique Mendonça Ferraz

José Carlos Marques

tas aqui analisadas, a presença aparente da polifonia: um discurso pensado e articulado por variadas vozes, especialmente, se pensarmos os diversos segmentos jornalísticos que adotam o jogador como capa das edições. Entretanto, por mais polifônicas que sejam à primeira vista essas formações discursivas, podemos pensá-las também pelo seu caráter (resultado) convergente. Logo, acreditamos que a convergência no fenômeno Neymar Jr. possa ser entendida pela maneira uniforme com que o personagem é retratado por meio do status de celebridade (evidência tanto como esportista, quanto como personalidade midiática) e por meio da forma sistêmica em que as diferentes edições (de segmentos jornalísticos discrepantes) parecem estar coordenadas na edificação eufórica da estrela.

Cabe apenas referir que, entre as revistas selecionadas de todos os segmentos e temáticas, a única edição que estamparia Neymar de maneira dissonante e divergente, por não enaltecer explicitamente as características e qualidades do jogador, foi a edição da revista ESPN, de outubro de 2010. Assim, a publicação aproveitaria da situação conturbada da carreira de Neymar, em seu segundo ano como jogador de futebol (período em que de fato conseguiu sucesso), para propor o questionamento: "Neymar: Gênio ou Monstro?”.

A análise do discurso e as três formas de amar

O fenômeno midiático de Neymar Jr. no mercado brasileiro de revistas pode ser considerado um caso atípico em território nacional. Muito pelo fato do personagem conseguir estrelar 22 edições de revistas brasileiras, de cinco segmentos diferentes. Com isso, a Análise do Discurso como metodologia de pesquisa oferece condições e princípios importantes para interpretarmos a construção verbo-visual de Neymar Jr. como protagonista das revistas brasileiras - principalmente, pelo método de análise privilegiar uma leitura sobre as produções e efeitos de sentido dos discur- 


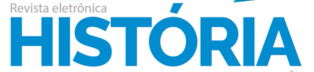

TRÊS FORMAS DE AMAR: A CONSTRUÇÃO DA IMAGEM DE NEYMAR JR NO MERCADO BRASILEIRO DE REVISTAS

Luís Henrique Mendonça Ferraz

José Carlos Marques

sos, tanto verbais, quanto não-verbais.

Dessa forma, ao analisarmos edição por edição das revistas brasileiras, temos como intuito detalhar e esmiuçar como as publicações nacionais selecionadas exemplares e edições que são enunciadores - construíram resolutamente discursos verbais e não-verbais confirmantes sobre a posição de Neymar Jr. como craque/celebridade em suas edições - particularmente, por darem ênfase e/ou optarem pela escolha de determinadas palavras, expressões e imagens. Com isso, a escolha do arcabouço metodológico da Análise do Discurso torna-se imprescindível para a nossa pesquisa, principalmente, quanto tomamos as definições tanto de Milton José Pinto (1999), quanto de Maria Gregolin (1995) sobre a aplicabilidade da AD. De acordo com Milton Pinto, "a Análise do Discurso não se interessa tanto pelo que o texto diz ou mostra, pois não é uma interpretação semântica de conteúdos, mas sim em como diz e por que o diz e mostra” (PINTO, 1999, p.23). Para Maria do Rosário Gregolin (1995), a Análise do Discurso procura e/ou busca por um detalhamento do discurso, revelando assim, com maior limpidez os valores que compõem determinado texto. Para a autora [...]

Na Análise do Discurso subjacente a um texto, podemos acompanhar as projeções da enunciação no enunciado; os recursos de persuasão utilizados para a verdade do texto (relação enunciador/enunciatário) e os temas e figuras utilizados. A enunciação pode ser reconstruída pelas "marcas" espalhadas no enunciado; é no discurso que se percebem com maior clareza os valores sobre os quais se assenta o texto. Analisar o discurso é, por isso, determinar as condições de produção do texto (GREGOLIN, 1995, p. 19).

Surgida na França, a AD representava uma tentativa de suprir as insuficiências da análise de conteúdo praticada nas ciências humanas e que se ocupava apenas da projeção de uma realidade extradiscursiva, não levando em conta as articulações linguísticas e textuais da obra. A Análise do Discurso, por sua vez, preocupou-se logo em fazer uma análise textual, realçando o modo de funcionamento lin- 
HISTÓRIA

TRÊS FORMAS DE AMAR: A CONSTRUÇÃO DA IMAGEM DE NEYMAR JR NO MERCADO BRASILEIRO DE REVISTAS

Luís Henrique Mendonça Ferraz

José Carlos Marques

guístico-textual dos discursos (PÊCHEUX, 1990; DUCROT, 1987), especialmente os ligados à publicidade e ao jornalismo.

Em sua gênese, a AD de linha francesa originou-se de três práticas notadamente europeias: a da tradição filológica; a da explicação de textos como exercício de leitura (comum no aparelho escolar francês); e a do estruturalismo. O pensamento dominante nesse momento é o de Louis Althusser (que procedeu a uma releitura das ideias marxistas), por meio dos estudos de Michel Pêcheux. Este concebe uma nova teoria do discurso que serviria, assim, para dar conta daqueles estudos que procuravam ver, na linguagem, um lugar privilegiado de materialização da ideologia. Esse objeto complexo que é a linguagem passa a ser concebido não apenas em seu componente linguístico, mas também em seu componente sócio-ideológico que a linguística saussuriana não abarcava (INDURSKI \& FERREIRA, 1999).

Uma discussão pertinente às ciências da linguagem diz respeito ao conceito da subjetividade. No plano da linguagem, o conceito de subjetividade é vislumbrado a partir de três momentos: a) o inaugurado por Émile Benveniste (1976) e que mostra a subjetividade como uma busca da constituição do sujeito no interior de seu discurso; b) outro influenciado pela teoria da ideologia e que mantém a questão do sujeito no quadro de uma formação ideológica e discursiva; c) e, por último, o momento que, influenciado pelo russo Mikhail Bakhtin e pela psicanálise, vê o discurso como espaço marcado por heterogeneidades, donde surge um sujeito dividido, que procura harmonizar as diferentes vozes presentes em sua fala em busca da unidade e da coerência (GREGOLIN \& BARONAS, 2001).

Além da subjetividade, outro conceito advindo da Análise do Discurso e que se instala confortavelmente na leitura do jornalismo é o que relaciona a categoria dos pressupostos e implícitos estabelecidos por Oswald Ducrot (1987). Segundo ele, o ato de pressupor configura-se numa tática argumentativa, na qual o enunciador leva o enunciatário a aceitar o conteúdo pressuposto por força da utilização de um discurso persuasivo-argumentativo. Nas definições de Dominique Maingueneau, o 
HISTÓRIA

TRÊS FORMAS DE AMAR: A CONSTRUÇÃO DA IMAGEM DE NEYMAR JR NO MERCADO BRASILEIRO DE REVISTAS

Luís Henrique Mendonça Ferraz

José Carlos Marques

pressuposto inscreve-se na estrutura do enunciado, independentemente do contexto, enquanto o subentendido só funciona a partir do contexto: "o subentendido é inferido de um contexto singular e sua existência é sempre incerta; já o pressuposto é estável. O primeiro é tirado do enunciado, o segundo da enunciação." (MAINGUENEAU: 1996, p. 92). Por último, interessa-nos a questão da produção de sentido no discurso jornalístico (BRAIT, 2003; RINGOOT, 2006) e a própria discussão epistemológica que envolve as teorias do jornalismo, sintetizadas nas obras dos pesquisadores portugueses Nélson Traquina $(2004,2005)$ e Adriano Duarte Rodrigues (2002).

O ídolo esportivo, o sex symbol e homem de sucesso, "a três formas de amar", são condições de produção presentes em grande parte dos discursos (verbais e não verbais) que circundam a representação midiática de Neymar Jr. no mercado brasileiro de revistas. A seguir, a fim de expormos tal mecânica adotada pelo segmento impresso nacional na construção de Neymar Jr. como celebridade, selecionamos e analisamos três casos emblemáticos e exemplares: os exemplares da Revista Veja, edição $n^{\circ} 2223$, da Revista TPM, edição $n^{\circ} 116$, e da Revista Época, edição $n^{\circ} 656$.

\section{O ídolo esportivo}

Com o título "Reymar", a edição da revista Veja trabalhou o sucesso esportivo de Neymar por meio de uma aproximação entre o grande jogador da atualidade e um ídolo do passado, já que na imagem temos o rosto de Neymar e na linha fina temos a "presença" textual de Pelé. Desta forma, a constituição da capa (verbal e não-verbal) aludiria para que a sucessão do reinado do futebol brasileiro seria de Neymar. Para exemplificarmos a "construção" produzida pela revista selecionaremos as principais formações discursivas e imagéticas existentes na capa da publicação: 


\section{HISTÓRIA}

TRÊS FORMAS DE AMAR: A CONSTRUÇÃO DA IMAGEM DE NEYMAR JR NO MERCADO BRASILEIRO DE REVISTAS

Luís Henrique Mendonça Ferraz

José Carlos Marques

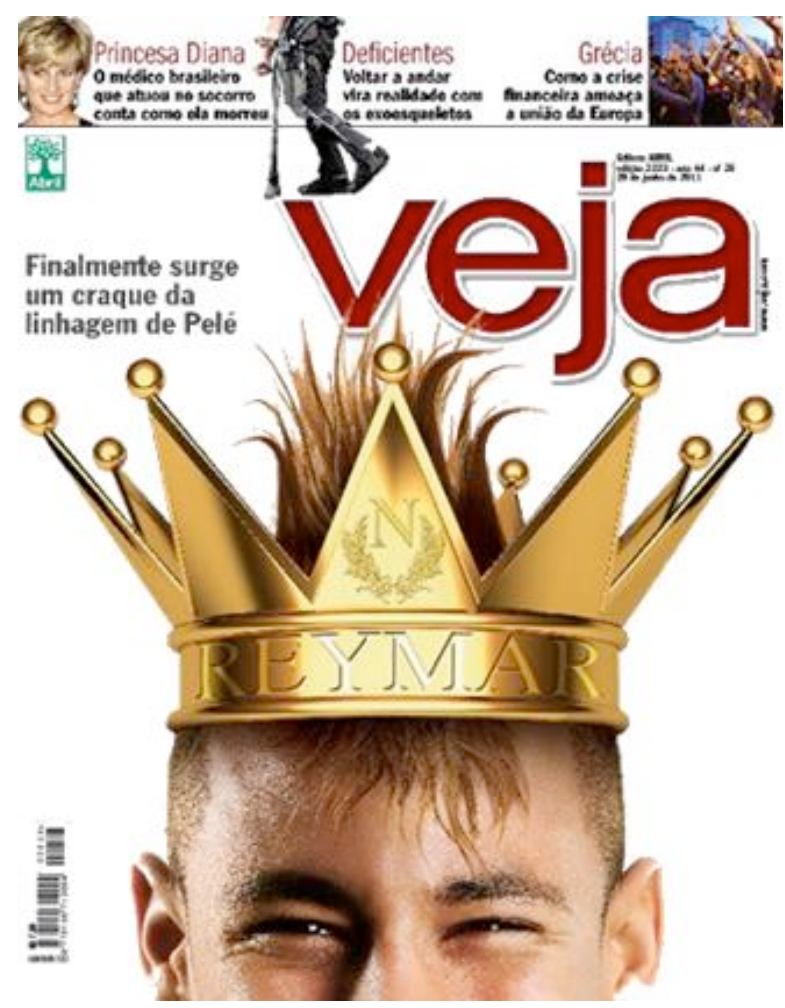

Imagem 1: Revista Veja, ed. $n^{\circ}$ 2223, de 29 de junho de 2011.

Título: Reymar

Linha Fina: Finalmente surge um craque da linhagem de Pelé

Imagem (não verbal): A coroa na cabeça de Neymar com a gravação "Reymar"

O título "Reymar" daria a entender o status adquirido por Neymar no futebol brasileiro, especialmente após a jornada vitoriosa do jogador entre os anos de 2010 e 2011. De maneira semelhante, a linha fina, na parte superior da página, complementaria a ideia do que representa o reinado de Neymar no país, ou seja, de que jogador que seria um "craque" aos moldes de Pelé - maior jogador de futebol brasileiro de todos os tempos e "eleito" pelo jornal esportivo francês L'Équipe como o 


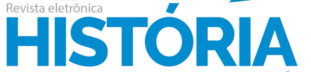

TRÊS FORMAS DE AMAR: A CONSTRUÇÃO DA IMAGEM DE NEYMAR JR NO MERCADO BRASILEIRO DE REVISTAS

Luís Henrique Mendonça Ferraz

José Carlos Marques

atleta do século $X X$. Consequentemente, na linha fina "finalmente surge um craque da linhagem de Pelé", temos os indicativos de que os feitos de Neymar dentro de campo estariam na esteira hereditária das conquistas de Pelé. Ademais, podemos entender, de acordo com a edição da Veja, que Neymar seria o maior jogador brasileiro após o término da carreira de Pelé como jogador de futebol profissional.

Da mesma forma, a palavra "linhagem" faz menção à descendência de Neymar como sucessor natural de Pelé, ou seja, se Pelé é o "rei" do futebol, Neymar é o herdeiro do trono futebolístico no país. Por conseguinte, a coroa que está sobre a cabeça de Neymar não traz a palavra "Rei", mas sim "Reymar" - numa ressignificação do próprio título da nobreza, agora incorporando o próprio nome do jogador.

Outra construção presente na edição em questão fica por conta do não dito, ou do que a publicação deixa implícito, que é tão importante quanto à formação discursiva presente na capa da edição. Desta maneira, ao utilizar a linha fina, principalmente por intermédio da palavra "finalmente", a publicação negligencia o passado bem documentado do futebol brasileiro e de seus craques. Neste sentido, são esquecidos outros tantos jogadores campeões mundiais, a exemplo de Ronaldo e Romário, atletas que são reconhecidos mundialmente tanto pelos seus desempenhos em clubes (nacionais e internacionais) quanto pela seleção brasileira de futebol. Consecutivamente, acreditamos que a revista Veja exagera na comparação, da qual consideramos precoce, de que Neymar seja o "próximo" Pelé, uma vez que o jogador cumpria apenas duas temporadas como profissional até aquela oportunidade.

\section{O sex symbol}

Sob o título de "Neymar é nosso", a Revista TPM destacaria que a edição do mês contaria com um "ensaio fotográfico revelador" do jogador. Assim, ao desnudar/despir Neymar em seu exemplar - como um feito inédito acionado pelo uso da palavra "revelador" -, a revista proporia para as mulheres (leitoras e consumidoras 


\section{HISTÓRIA}

TRÊS FORMAS DE AMAR: A CONSTRUÇÃO DA IMAGEM DE NEYMAR JR NO MERCADO BRASILEIRO DE REVISTAS

Luís Henrique Mendonça Ferraz

José Carlos Marques

do conteúdo) que o jogador/celebridade seria delas como nunca havia sido de ninguém, ou seja, de qualquer outra publicação. Logo, o título da revista salientaria a falta de roupa (a novidade de vê-lo num ensaio fotográfico exclusivo) pela expressão "Neymar é nosso".

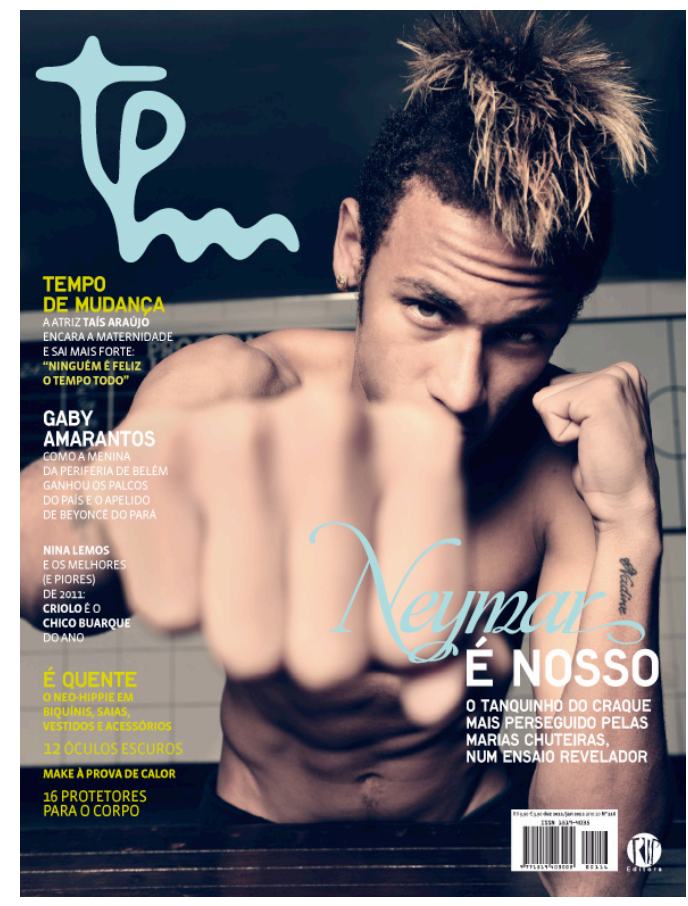

Imagem 2: Revista TPM, ed. 116, dezembro de 2011.

Título: Neymar é nosso

Linha fina: O tanquinho do craque mais perseguido pelas Marias chuteiras, num ensaio revelador

Imagem (não-verbal): Neymar sem camisa e simulando um soco.

O pronome "nosso" utilizado pela publicação também intensificaria a ideia sobre "posse" do corpo de Neymar, particularmente pela capa da edição dar enfoque ao físico (ao corpóreo) do astro midiático. Consequentemente, ao conceder desta- 


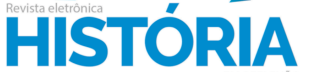

TRÊS FORMAS DE AMAR: A CONSTRUÇÃO DA IMAGEM DE NEYMAR JR NO MERCADO BRASILEIRO DE REVISTAS

Luís Henrique Mendonça Ferraz

José Carlos Marques

que para o corpo - para o músculo oblíquo externo e a barriga definida expostos pela imagem (não-verbal) - a publicação revelaria o desejo das mulheres por Neymar, à atração física pela celebridade.

A publicação ainda promoveria Neymar ao estatuto de grande jogador de futebol, sobretudo, pela formação discursiva da linha de apoio: "O tanquinho do craque mais perseguido pelas Marias chuteiras". Logo, a palavra "craque" e o termo "Marias chuteiras" presentes na capa da edição da revista TPM dariam os indícios sobre o êxito de Neymar como esportista bem-sucedido e como sex symbol para o público feminino. Prontamente, a expressão “Marias chuteiras" caracterizaria as meninas que perseguem os jogadores de futebol, particularmente os conhecidos/famosos, na tentativa de ter algum relacionamento íntimo com eles.

Obviamente, a revista TPM não chama suas leitoras de "Marias chuteiras", no entanto, ao revelar a existência deste tipo de meninas deixaria implícito que a proeminência de Neymar não é feita apenas pela beleza, pela sensualidade e pela atração física, mas de um ícone que seria acionado por algo que estivesse além do corpo. Sendo assim, entendemos que se Neymar não fosse a maior revelação do futebol brasileiro - um homem de sucesso e de enorme participação na mídia -, o mistério e o desejo pelo secreto (pelo corpo) não teriam grande impacto (importância) para a publicação e para suas consumidoras.

\section{O homem de sucesso}

O ano de 2010, com toda a certeza, marcaria a ascensão de Neymar como grande celebridade brasileira, primordialmente, por ser o período em que a carreira do jogador/celebridade sofre um "boom" - crescimento acelerado tanto desportivo quando midiático poucas vezes visto (num curto espaço de tempo) no Brasil. Consecutivamente, a revista Época, de dezembro de 2010, seria a primeira publicação nacional (do mercado de revistas) que proporia Neymar como um homem de sucesso 


\section{HISTÓRIA}

TRÊS FORMAS DE AMAR: A CONSTRUÇÃO DA IMAGEM DE NEYMAR JR NO MERCADO BRASILEIRO DE REVISTAS

Luís Henrique Mendonça Ferraz

José Carlos Marques

no país.

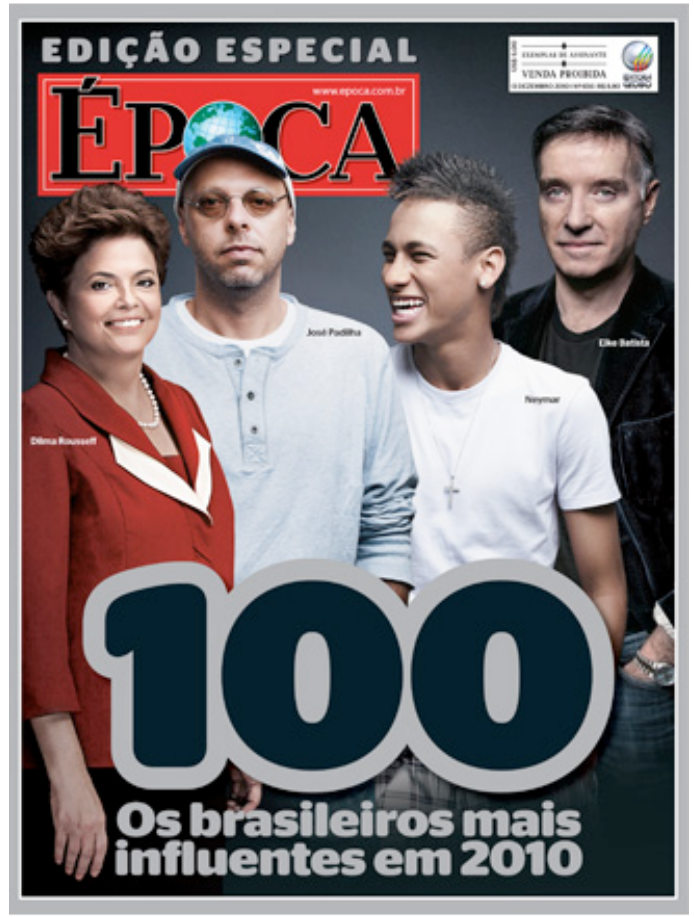

Imagem 3: Revista Época, ed. n 656, de 11 de dezembro de 2010.

Título: 100

Linha fina: Os brasileiros mais influentes de 2010

Imagem (não-verbal): Fotomontagem composta pelas personalidades Dilma Rousseff, José Padilha, Eike Batista e Neymar

Com o título de "100" e com a linha fina "os brasileiros mais influentes em 2010" a publicação colocaria lado a lado alguns dos personagens escolhidos como as pessoas brasileiras mais influentes pelo talento e pelo poder no período. Para tanto, a edição faria duas construções, uma verbal e outra não-verbal, ambas complementares. Neste sentido, o título e a linha fina da publicação "100: os brasileiros mais influentes em 2010" atuariam em conjunção com a fotomontagem da capa da revista. Enquanto a formação discursiva exporia os cem brasileiros, o discurso não- 


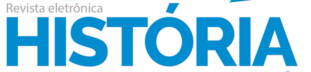

TRÊS FORMAS DE AMAR: A CONSTRUÇÃO DA IMAGEM DE NEYMAR JR NO MERCADO BRASILEIRO DE REVISTAS

Luís Henrique Mendonça Ferraz

José Carlos Marques

verbal apresentado pela "primeira-página" mostraria apenas quatro. Logo, podemos compreender que os personagens estampados como figuras-principais seriam os classificados (no sentido de avaliação) pelo exemplar como mais importantes do que os outros noventa e seis, que não foram sequer citados pela capa da edição. Consequentemente, o título da revista "100: os brasileiros mais influentes em 2010" converte-se em: "4: os brasileiros mais importantes de 2010".

A interpretação da imagem (não-verbal) formaria também um discurso sobre o pioneirismo - de quem é precursor, de quem está à frente de outros pelo êxito profissional - dos "eleitos" pela publicação como grandes referências nacionais. Por conseguinte, o discurso imagético da edição, por meio de uma sequência de personagens, destacaria: Dilma Rousseff, José Padilha, Eike Batista e Neymar. Respectivamente, o não-verbal também formaria o discurso: a primeira mulher presidente do Brasil, o cineasta recordista de bilheteria no país pela produção de "Tropa de Elite 2", o empresário brasileiro mais rico (naquela época dono da sétima fortuna do mundo) e a grande estrela do futebol nacional.

Em dezembro de 2010, momento em que a revista ganharia as bancas nacionais, Neymar já era considerado pela mídia esportiva nacional como o grande nome do futebol brasileiro dos últimos tempos. Além dos títulos conseguidos em campo, o ano de 2010 foi, com toda a certeza, o momento em que Neymar deixou de ser apenas a maior aposta do futebol do brasileiro. Naquele período, a fama do jogador extrapolaria seu desenvolvimento enquanto profissional do futebol, logo, a capa da revista Época destacaria Neymar não apenas como novo craque do futebol brasileiro, mas também como celebridade nacional. Ademais, a "primeira página" da revista Época revelaria Neymar como um dos quatro brasileiros mais influentes do Brasil e, consequentemente, um dos homens de sucesso de maior importância e relevância da nação - particularmente, pelas relações de poder que emanam da fotomontagem, por Neymar estar ao lado do Chefe de Estado e do empresário bilionário brasileiro. 


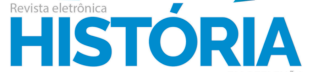

TRÊS FORMAS DE AMAR: A CONSTRUÇÃO DA IMAGEM DE NEYMAR JR NO MERCADO BRASILEIRO DE REVISTAS

Luís Henrique Mendonça Ferraz

José Carlos Marques

\section{Considerações finais}

Em 2010, fica explícito que as revistas nacionais abordavam preferencialmente as virtuosidades de Neymar Jr. enquanto esportista, ou seja, de que sua exposição midiática tenha surgido e/ou tenha sido motivada pela sua jornada vitoriosa como jogador profissional de futebol. As primeiras veiculações da imagem do atleta foram promovidas pelo poder do esporte como paixão nacional e, consequentemente, pelo arquétipo de craque exercido pelo ícone.

Nos anos de 2011 e 2012, após a ascensão como fenômeno esportivo, a imagem de Neymar Jr. transitou por outras áreas, conteúdos e temáticas - tanto do jornalismo como do entretenimento nacional. Assim sendo, os meios de comunicação brasileiros, em sua generalidade, acabaram atribuindo novos papéis para o desempenho de Neymar Jr. no cenário midiático. Desta forma, a consolidação da personalidade midiática que nasceu dentro da esfera esportiva foi transcendida e disseminada para outros âmbitos do jornalismo e do entretenimento nacional, transformando-o em um dos personagens mais constantes dos veículos de comunicação brasileiros. Em conformidade, o fato pôde ser acompanhado também no mercado de revistas brasileiro, momento em que a personalidade midiática ora era mais jogador de futebol ora era mais popstar, ou mesmo cumpriu as duas funções simultaneamente.

A análise do corpus da pesquisa possibilitou uma leitura importante para que pudéssemos compreender a participação de Neymar como estrela do mercado brasileiro de revistas. Consecutivamente, cremos que as funções majoritariamente ocupadas e exercidas pela celebridade responderam a três categorias dominantes: a do ídolo esportivo, a do sex symbol e a do homem de sucesso.

Com a criação das três categorias de análise - neste artigo, "as três formas de amar" a celebridade -, por mais que cada publicação tenha dado enfoque discur- 


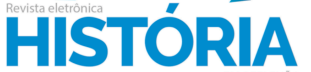

TRÊS FORMAS DE AMAR: A CONSTRUÇÃO DA IMAGEM DE NEYMAR JR NO MERCADO BRASILEIRO DE REVISTAS

Luís Henrique Mendonça Ferraz

José Carlos Marques

sivamente e imageticamente a personalidade midiática a sua maneira - dentro dos padrões e segmentos jornalísticos, com gêneros e temáticas próprias -, percebemos que a "construção" da imagem de Neymar teve um princípio norteador: no caso, a preservação e a consagração de um potente ícone midiático, um dos mais efervescentes e apelativos na interação (contato) com o público durante os anos de 20102011-2012. Logo, o fio que conduziu o desenvolvimento do ícone no mercado de revistas foi prontamente colocado em ação pelo uso de reiterações e repetições verbo-visuais que o confirmavam como celebridade nacional.

Como pudemos presenciar no mercado de revistas brasileiro, a mídia optou por criar e perpetuar certas facetas de Neymar Jr. - ocultando algumas passagens polêmicas da vida pessoal e profissional do jogador/celebridade - para que o mesmo não tivesse grandes rejeições no contato e na interação com a plateia. Se pensarmos na "construção" da imagem de Neymar enquanto protagonista só podemos chegar à conclusão de que a representação midiática do jogador como celebridade no país foi profícua, ou seja, de que os meios de comunicação brasileiros conseguiram realmente agendar e mediar a participação de Neymar como um indivíduo valoroso, influente e importante.

As revistas brasileiras, como integrantes dos meios de comunicação de massa brasileiros, podem indicar também que a produção dos discursos hegemônicos, sistêmicos, convergentes e eufóricos que promovem Neymar Jr. não é restrita apenas ao segmento impresso analisado. De certa forma, acreditamos que o povo brasileiro acompanhou, mesmo que sem querer, o desenvolvimento profissional e pessoal de Neymar Jr. frente às câmeras. Temos imagens suas desde criancinha contando sobre o seu sonho em ser jogador de futebol profissional; falando sobre o desejo de jogar uma Copa do Mundo. Com isso, acreditamos que a afetividade, interação e contato com o personagem foram feitos por uma representação midiática (construção da imagem) que privilegiou determinadas particularidades. As facetas que corriqueiramente selecionadas e produzidas pela mídia sempre valorizaram um Neymar 


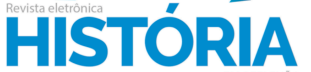

TRÊS FORMAS DE AMAR: A CONSTRUÇÃO DA IMAGEM DE NEYMAR JR NO MERCADO BRASILEIRO DE REVISTAS

Luís Henrique Mendonça Ferraz

José Carlos Marques

Jr. alegre, festivo, bonito, bom-moço. Mesmo com todo o talento, fama e dinheiro, a celebridade teve conservado o ar jovial e inocente de garoto.

Acompanhamos um adolescente que se transformou em adulto numa espécie de reality show promovido pelo futebol e pela mídia esportiva nacional que, consecutivamente, foi entrelaçado com outros conteúdos, programas e produtos do entretenimento. E esse fato faz dele o maior símbolo do esporte nacional e uma das celebridades brasileiras de maior evidência.

No triênio 2010-2011-2012, os anos em que o jogador realmente ratificou a posição como grande jogador de futebol, inúmeros foram os programas de televisão, portais da internet, jornais impressos e revistas, que notabilizaram a vida pessoal e profissional de Neymar Jr., culminando na criação de uma vigorosa celebridade midiática. Evidentemente, a comoção e o sentimentalismo do público só confirmam a ideia que a mídia conseguiu projetá-lo para fora de seus domínios. Portanto, entre o ídolo esportivo, o sex symbol e o homem de sucesso, temos a criação de uma celebridade total - das celebridades como produto da mídia, como enfatiza Rüdiger como poucas vezes vimos em território nacional.

Trata-se de um personagem que atende aos interesses dos meios de comunicações e dos patrocinadores globais - moda e estilo de vida. Temos uma narrativa midiática eufórica e sistêmica, a qual, por meio de três formas de amar, atrela sua imagem à dos símbolos/representações do sucesso profissional, do símbolo sexual e da mimese adolescente, a par de sua afirmação como jogador extraordinário e fora-de-série. Nesse sentido, o jogador assume a persona de quem atende a uma demanda previamente programada e agendada pelos veículos de comunicação.

Com a ida de Neymar para o exterior em 2013, o processo de exposição nas capas de revistas brasileiras reduziu-se, ao mesmo tempo em que o atleta ganhou nova dimensão no mercado global futebolístico. Acreditamos que ele tenha sido capa de um sem número de revistas europeias, especialmente na Espanha e na França, pelo fato de ter atuado num clube espanhol (o Barcelona) de 2013 a 2017 e de 


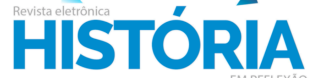

TRÊS FORMAS DE AMAR: A CONSTRUÇÃO DA IMAGEM DE NEYMAR JR NO MERCADO BRASILEIRO DE REVISTAS

Luís Henrique Mendonça Ferraz

José Carlos Marques

estar atuando num clube francês (o PSG) desde 2017. Trata-se de um novo universo a ser desvendado em futuros estudos que possam derivar desta nossa proposta de leitura aqui apresentada.

\section{Referências}

BENVENISTE, Émile. Da subjetividade na linguagem. Problemas de Lingüística Geral. São Paulo, Editora Nacional/Edusp, 1976.

BRAIT, Beth. Leituras, significações, efeitos de sentido. Revista Líbero, São Paulo: Editora Facasper, Ano VI, v. 6, n. 11, 2003.

BRANDÃO, Helena H. Nagamine. Introdução à Análise do Discurso. Campinas: Editora da Unicamp, 1997.

DUCROT, Oswald. O dizer do dito. Campinas, Pontes, 1987.

FOUCAULT, Michel. A ordem do discurso. 6ª ed., São Paulo, Loyola, 1996.

GREGOLIN, Maria do Rosário e BARONAS, Roberto (org.). Análise do discurso: as materialidades do discurso. São Carlos, Claraluz, 2001.

GREGOLIN, Maria do Rosário. Revista Alfa. São Paulo, n. 39, p.13-21. 1995.

GUEDES, Simoni Lahud. O salvador da pátria: considerações em torno da imagem do jogador Romário na Copa do Mundo de 1994. Revista do núcleo de Sociologia do Futebol, Rio de janeiro, n.1, p. 23-41,1995.

HELAL, Ronaldo. A construção de narrativas de idolatria no futebol brasileiro. Revista Alceu, Rio de Janeiro. v. 4, n.7, p. 19-36, 2003.

INDURSKI, Freda e FERREIRA, Maria Cristina Leandro (org.). Os múltiplos territórios da Análise do Discurso. Porto Alegre: Sagra Luzzato, 1999.

KELLNER, Douglas. A cultura da mídia. Bauru: EDUSC, 2001.

KELLNER, Douglas. A cultura da mídia e o triunfo do espetáculo. Revista Líbero. 
HISTÓRIA

TRÊS FORMAS DE AMAR: A CONSTRUÇÃO DA IMAGEM DE NEYMAR JR NO MERCADO BRASILEIRO DE REVISTAS

Luís Henrique Mendonça Ferraz

José Carlos Marques

Ano VI, v. 6, n. 11, p. 4-15, 2004.

MAINGUENEAU, Dominique. Pragmática para o discurso literário. São Paulo, Martins Fontes, 1996.

MARQUES, José Carlos. O mito construído, destruído e reconstituído: o caso cíclico de Ronaldo fenômeno. In: Congresso da Sociedade Brasileira de Estudos Interdisciplinares da Comunicação, 28., Rio de Janeiro: 2005. [Anais...] São Paulo: INTERCOM, 2005., p. 1- 16. Disponível em:

http://www.portcom.intercom.org.br/pdfs/13500668043939080857310945707666768 3757.pdf

MORIN, Edgar. As estrelas: mito e sedução no cinema. Rio de Janeiro; José Olympio, 1989.

MORIN, Edgar. O cinema ou o homem imaginário. Lisboa, Portugal: Relógio D’Água/Grande Plano, 1997.

ORLANDI, Eni. Discurso e texto: formulação e circulação dos sentidos. Campinas, Pontes, 2001.

(org.). Gestos de leitura: da história no discurso. $2^{a}$ ed., Campinas, Editora da Unicamp, 1997.

PÊCHEUX, Michel. Análise automática do discurso, (1969), in GADET, F. \& HAK, T. Por uma análise automática do discurso. Campinas: Unicamp, 1990.

PINTO, Milton José. Comunicação e discurso: introdução à análise do discurso. São Paulo: Hacker Editores, 1999.

RINGOOT, Roselyne. "Por que e como analisar o discurso no contexto dos estudos sobre Jornalismo?”. In: Comunicação e Espaço Público., Brasília: Editora UNB Ano 9, n. 1 e 2, 2006.

RODRIGUES, Adriano Duarte. Delimitação, natureza e funções do discurso midiático. In: Maurice Mouillaud (org.). O jornal: da forma ao sentido., Brasília: Editora UNB, v.2, n.2, p. 217-234, 2002.

RÜDIGER, Francisco (org.). Roberto Carlos, Xuxa e os barões da mídia: estudos sobre a fama, sucesso e celebridade no Brasil. Porto Alegre: Gattopardo, 2008. 


\section{HISTÓRIA}

TRÊS FORMAS DE AMAR: A CONSTRUÇÃO DA IMAGEM DE NEYMAR JR NO MERCADO BRASILEIRO DE REVISTAS

Luís Henrique Mendonça Ferraz

José Carlos Marques

SCALZO, Marília. Jornalismo de Revista. 2. ed. São Paulo: Contexto, 2004.

SIMÕES, Paula Guimarães. A mídia e a construção das celebridades: uma abordagem praxiológica. Revista Logos. v.16, n. 2, p. 67-79, 2010.

Artigo recebido em 24/08/2018

Artigo aceito em 22/12/2018 